\title{
Scleritis and anterior uveitis may herald the development of an epibulbar tumor in patients with extranodal Rosai-Dorfman disease: a case report
}

\author{
Yu-Kuei Lee ${ }^{1}$, Sheau-Chiou Chao ${ }^{2}$, Chaw-Ning Lee ${ }^{2}$ and Jia-Horung Hung ${ }^{1,3^{*}}$ (i)
}

\begin{abstract}
Background: Rosai-Dorfman disease is a rare non-Langerhans cell histiocytosis. Ocular involvement is even rarer, mostly involving the orbit and eyelids, although marginal corneal ulcers, uveitis, and epibulbar masses have also been reported, and is characterized by multiple recurrences. However, the disease course and optimal treatment strategies remain undetermined, in light of the rarity of this disease.

Case presentation: We reported a 36-year-old male patient with the extranodal form of Rosai-Dorfman disease, presenting with scleritis and anterior uveitis in the left eye, who experienced subsequent development of an epibulbar tumor in the same eye. The patient was also complicated by a relapsing facial nodule on the right cheek. After the pathological diagnosis of Rosai-Dorfman disease was obtained, the patient underwent surgical excision of the epibulbar tumor and the facial nodule, accompanied by systemic immunosuppression therapy. At the last follow-up, the patient was asymptomatic without signs of recurrence.
\end{abstract}

Conclusions: This report highlights the progression of ocular manifestations of Rosai-Dorfman disease and emphasizes the importance of systemic therapy.

Keywords: Rosai-Dorfman disease, Epibulbar tumor, Histiocytosis

\section{Background}

Rosai-Dorfman disease (RDD) is a rare non-Langerhans cell histiocytosis that is characterized by the accumulation of activated histiocytes within affected tissues, and it usually presents with prominent cervical lymphadenopathy [1]. Ocular involvement of RDD is even rarer and mostly involves the orbit and eyelids, although marginal corneal ulcers, uveitis, and epibulbar masses have also been reported [1-4]. Herein, we report an unusual case of RDD with ocular and dermatological findings, including scleritis and anterior uveitis and the subsequent development of an epibulbar tumor, and was complicated by a relapsing facial nodule.

\footnotetext{
* Correspondence: hungjh@mail.ncku.edu.tw

'Department of Ophthalmology, National Cheng Kung University Hospital, College of Medicine, National Cheng Kung University, Tainan, Taiwan

${ }^{3}$ Institute of Clinical Medicine, College of Medicine, National Cheng Kung

University, Tainan, Taiwan

Full list of author information is available at the end of the article
}

\section{Case presentation}

A 36-year-old male with an unremarkable medical history presented to the ophthalmology service with a 1month history of a congested and painful left eye accompanied by a persistent left-sided headache. Ophthalmologic examination revealed a best corrected visual acuity of 20/20 for both eyes and an intraocular pressure of 20 and $15 \mathrm{mmHg}$ for the right and left eyes, respectively. Biomicroscopy revealed significant conjunctival injection with engorged vessels in the temporal aspect of the patient's left eye (Fig. 1a), which did not blanch after instillation of $10 \%$ phenylephrine. The cornea was clear, and $3+$ cells were visualized in the left anterior chamber. The results of a dilated fundoscopic examination were normal. Laboratory studies demonstrated an elevated Creactive protein level $(25.7 \mathrm{mg} / \mathrm{L})$ and erythrocyte sedimentation rate $(32 \mathrm{~mm} / \mathrm{h})$. A thorough rheumatologic evaluation was unrevealing, and the following tests were

(c) The Author(s). 2019 Open Access This article is distributed under the terms of the Creative Commons Attribution 4.0 International License (http://creativecommons.org/licenses/by/4.0/), which permits unrestricted use, distribution, and reproduction in any medium, provided you give appropriate credit to the original author(s) and the source, provide a link to the Creative Commons license, and indicate if changes were made. The Creative Commons Public Domain Dedication waiver (http://creativecommons.org/publicdomain/zero/1.0/) applies to the data made available in this article, unless otherwise stated. 

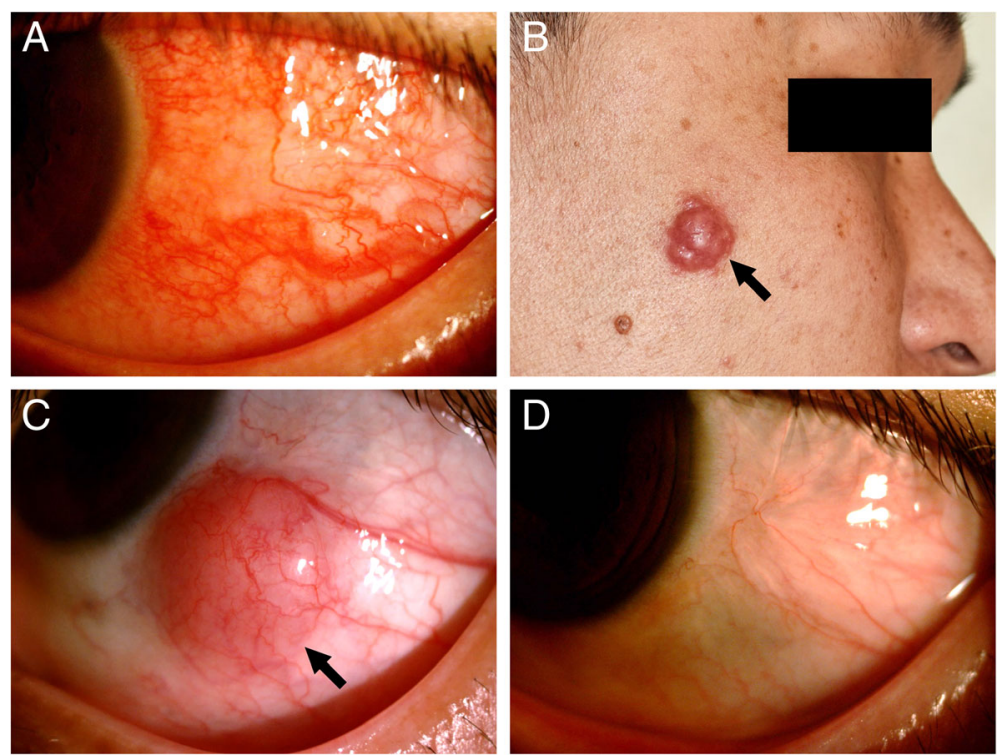

Fig. 1 Clinical appearance of Rosai-Dorfman disease (RDD) with ocular and dermatological involvement in a 36-year-old male: (a) Slit-lamp photograph of his left eye demonstrating engorged conjunctival vessels and a significantly injected bulbar conjunctiva. b RDD of the skin showing a $1.5 \times 1.3-\mathrm{cm}$ erythematous soft lobulated nodule, over right face (arrow) on the right cheek. c Clinical photographs depicting a wellcircumscribed, epibulbar nodule (arrow) at the inferior-temporal aspect of the eyeball after six-months of follow-up. Note that the location of the nodule is essentially similar to that of the scleritis observed in Panel A. $\mathbf{d}$ Clinical appearance of the left eye showing a quiet conjunctiva without evidence of tumor recurrence at follow-up 24 months later

normal, including total and differential white blood cell counts, rheumatoid factor, antinuclear antibodies, antineutrophil cytoplasmic antibodies, serology for syphilis and chest X-ray. A diagnosis of scleritis was made, and the patient received $40 \mathrm{mg}$ oral prednisolone daily and topical $1 \%$ prednisolone 4 times daily. Though the ocular symptoms improved, the resolution was incomplete.

Four weeks later, the patient was referred to the dermatology service because physical examination revealed a rapidlygrowing erythematous soft lobulated nodule $(1.5 \times 1.3 \mathrm{~cm})$ on the right side of the patient's face (Fig. 1b). An incisional biopsy specimen was obtained, and the pathological findings showed dense diffuse nodular infiltrate of epithelioid and multinucleated histiocytes with S-100 positivity mixed with neutrophils throughout the upper two-thirds of the dermis, which was consistent with atypical Rosai-Dorfman disease with abundant neutrophils. The facial nodule continued to grow while the patient was maintained on low-dose prednisolone ( $5 \mathrm{mg}$ daily). Although intralesional triamcinolone injections were performed weekly for 5 weeks, the tumor continued to enlarge to $4 \times 2.5 \mathrm{~cm}$, so excision of the facial skin tumor was performed. The pathological diagnosis was RDD with excessive Demodex mites. The maintenance therapy included prednisolone and doxycycline along with prn intralesional triamcinolone injections.

Two months after the skin surgery, a painless, fixed, pink subconjunctival nodule was noted in the inferiortemporal aspect of his left eye (Fig. 1c), and surgical excision was scheduled. Pathological examination of the specimen demonstrated histiocytes with emperipolesis, cytoplasmic and nuclear S100 positivity, and a negative stain for CD1a, which were also compatible with RDD (Fig. 2a-d). In addition, 1 week after the ocular surgery, multiple discrete and confluent papulonodules rapidly evolved over the bilateral cheek, ear and scalp. Oral dapsone $100 \mathrm{mg}$ daily was administered for 6 weeks and was then switched to methotrexate (MTX) $10 \mathrm{mg}$ once weekly due to poor response. The patient underwent another excision of the tumor on the right side of his face and intermittent intralesional triamcinolone injections. Finally, the lesions gradually flattened, and MTX was then slowly tapered to a maintenance dose of $2.5 \mathrm{mg}$ per week after 4 months. At the 24-month follow-up, there were no signs of recurrence of the epibulbar tumor and facial mass or of involvement of other sites (Fig. 1d).

\section{Discussion and conclusions}

In this case report, we presented the successful management of a case with complex RDD that involved ocular and dermatological aspects. In addition, scleritis and anterior uveitis may foreshadow the development of an epibulbar tumor.

Ophthalmic involvement occurs in approximately $10 \%$ of patients with RDD $[2,5]$. In a recent review by Choi et al, $75 \%$ of ocular RDD cases presented with epibulbar masses [2]. Epibulbar masses were first reported as ophthalmic 


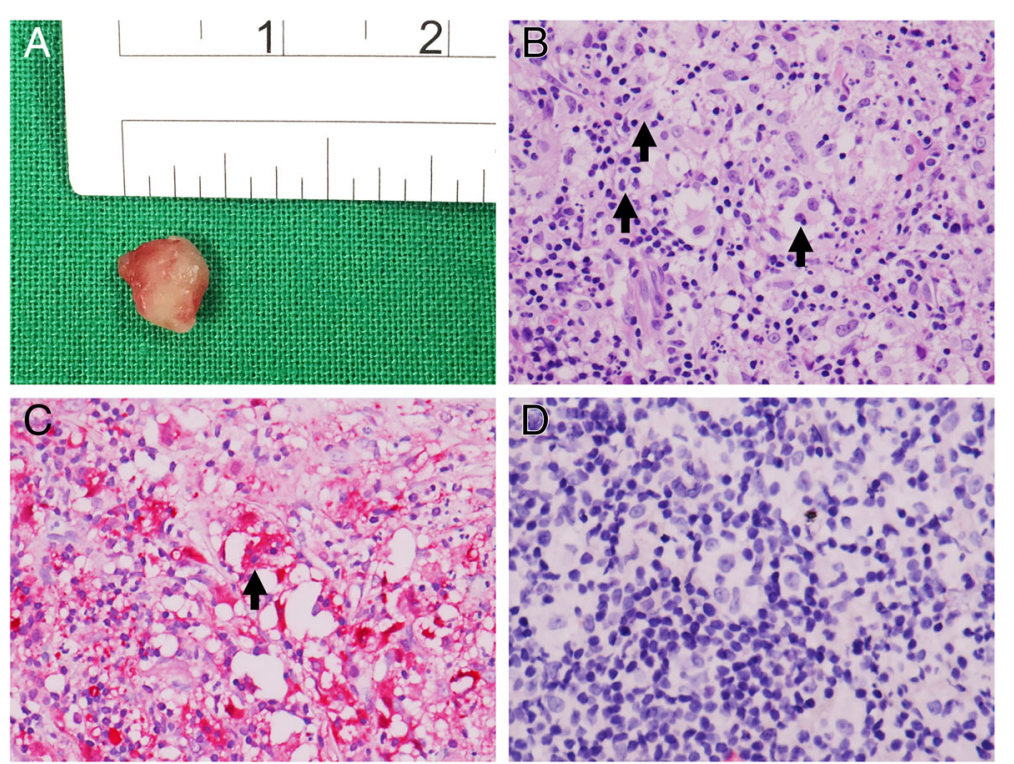

Fig. 2 Pathological study of Rosai-Dorfman disease (RDD). a The excisional epibulbar nodule (Gross view). b Photomicrographs revealing RDD histiocytes with emperipolesis (arrows) (hematoxylin and eosin stain; original magnification, $\times 400$ ). $\mathbf{c}$, d Immunohistochemical photomicrograph displaying the histiocytes with positive nuclear and cytoplasmic staining for S-100 (c) but negative staining for CD1a (d). The arrow in Panel c marks emperipolesis (original magnification, $\times 400$ )

manifestations in RDD by Zimmerman et al in 1988 in a 13year-old male patient [6]. Since then, several cases have been reported, of which 13\% (2 of 15 cases) also had dermatological presentations (Table 1) [2-4, 6-12]. Only one case of RDD has been reported with findings similar to the present case [9]. The ocular RDD presented with scleritis as the initial stage and was characterized by an incomplete response to corticosteroid treatment followed by the development of an epibulbar mass within months. However, there was no record of systemic involvement in that case [9].

Based on the clinical features, there are two types of RDD: one type is the classic nodal form, which is characterized by bilateral, massive, and painless cervical lymphadenopathy, and the other type is extranodal RDD [1]. Although extranodal RDD accounts for $43 \%$ of RDD cases, and the skin is involved in 10\% of extranodal RDD cases [1], cutaneous RDD that only affects the skin is extremely rare $[13,14]$. Whereas the histologic appearance of the cutaneous RDD is similar to that of systemic extranodal RDD, our case is a systemic RDD with multiple extranodal organ involvements.

It is theoretically possible that Demodex infestations might play a role in inducing RDD or aggravating the disease. Demodex mites parasitize healthy skin. Overgrowth of Demodex are found in rosacea patients, and it is speculated that the Demodex mites trigger the host immune response by the activation of the TLR2 pathway, leading to skin inflammation [15]. RDD coexists with inflammatory disease in $10 \%$ of cases, such as systemic lupus erythematous, erythematous, idiopathic juvenile arthritis, and autoimmune hemolytic anemia [1]. Despite the possible connection between the two disease entities, a literature review did not identify a study analyzing the relationship between Demodex infestations and RDD.

The standard treatment of RDD remains undetermined, although many therapeutic options, such as surgery, as well as chemotherapy, radiotherapy, oral corticosteroids, sirolimus, and immunomodulatory therapy, have been reported $[1,2,16]$. Observation of the patient rather than treatment is reasonable in many cases because up to $50 \%$ of patients with RDD have been reported to undergo spontaneous remission [1]. Nevertheless, observation alone is indicated only for patients with uncomplicated lymphadenopathy or asymptomatic cutaneous RDD and potentially for those with asymptomatic disease in other sites. Surgical excision can be curative for unifocal disease [3]; however, local recurrence may subsequently occur [4]. In our literature review, $40 \%$ (6 of 15 patients) had at least one recurrence (Table 1 ), and among these patients $33 \%$ ( 2 of 6 patients) did not receive systemic immunosuppressive therapy. The present case received various immunosuppressive regimens, including MTX as an effective maintenance therapy. The consensus recommends using low-dose methotrexate 20 $\mathrm{mg} / \mathrm{m}^{2}$ per week in refractory cases [1]. Based on our experience, methotrexate cold be tapered when RDD resolves. Methotrexate could be tapered to $2.5-5 \mathrm{mg}$ per week for 3-6 months as maintenance therapy. Long-term low-dose methotrexate is relatively safe, but blood counts and liver enzymes should be routinely monitored [17]. No evidence of local recurrence was noted in the present case, 
Table 1 Summary of Rosai-Dorfman disease manifesting as epibulbar masses

\begin{tabular}{|c|c|c|c|c|c|c|}
\hline Reference & $\begin{array}{l}\text { Age/ } \\
\text { Gender }\end{array}$ & Eye & Ophthalmic findings & Extraocular involvement & Treatment & Recurrence \\
\hline $\begin{array}{l}\text { Zimmerman, } \\
1988[6]\end{array}$ & $13 / \mathrm{M}$ & OS & Superior epibulbar nodule $(8 \times 6 \mathrm{~mm})$ & $\begin{array}{l}\text { Minimal inguinal } \\
\text { lymphadenopathy }\end{array}$ & Excision & No \\
\hline Tan, 2002 [7] & $63 / \mathrm{M}$ & OS & $\begin{array}{l}\text { Inferior epibulbar nodule }(5 \times 12 \mathrm{~mm}) \text {, } \\
\text { anterior modular scleritis, anterior and } \\
\text { posterior uveitis }\end{array}$ & $\begin{array}{l}\text { Post-auricular lymphadenopathy } \\
\text { and vocal cord nodule }\end{array}$ & $\begin{array}{l}\text { Excision + Oral \& topical } \\
\text { steroid }\end{array}$ & Yes \\
\hline \multirow[t]{2}{*}{$\begin{array}{l}\text { Albini, } 2005 \\
{[8]}\end{array}$} & 71/M & OD & $\begin{array}{l}\text { Nasal side epibulbar nodule }(15 \times 15 \\
\mathrm{mm})\end{array}$ & Nil & Excision & No \\
\hline & $51 / \mathrm{M}$ & OS & Nasal side epibulbar nodule (5 mm) & Nil & Excision & No \\
\hline \multirow[t]{2}{*}{$\begin{array}{l}\text { Sarwal, } 2008 \\
{[9]}\end{array}$} & $53 / F$ & OU & $\begin{array}{l}\text { Superotemporal epibulbar nodule }(3 \times 3 \\
\mathrm{mm}) \text {, anterior nodular scleritis, anterior } \\
\text { uveitis }\end{array}$ & $\begin{array}{l}\text { Anterior chest wall, abdominal } \\
\text { and pelvic masses }\end{array}$ & Excision + topical steroid & Yes \\
\hline & $19 / F$ & OS & $\begin{array}{l}\text { Superonasal epibulbar nodule }(3.25 \times \\
3.25 \mathrm{~mm}) \text {, nodular scleritis }\end{array}$ & Nil & Excision & No \\
\hline $\begin{array}{l}\text { Fernandes, } \\
2008[10]\end{array}$ & 19/M & OD & $\begin{array}{l}\text { Temporal epibulbar nodule }(12 \times 11 \\
\mathrm{mm}) \text {, conjunctival injection }\end{array}$ & Nil & Excision & Yes \\
\hline $\begin{array}{l}\text { Maheshwari, } \\
2008[11]\end{array}$ & $17 / \mathrm{M}$ & OS & Temporal epibulbar nodule $(3 \times 5 \mathrm{~mm})$ & Nil & Excision + oral steroid & No \\
\hline $\begin{array}{l}\text { De Oliveira, } \\
2011 \text { [3] }\end{array}$ & $14 / F$ & OD & $\begin{array}{l}\text { Inferior epibulbar nodule }(5 \times 15 \mathrm{~mm}) \text {, } \\
\text { conjunctival injection }\end{array}$ & Nil & Excision & No \\
\hline $\begin{array}{l}\text { Payne, } 2011 \\
{[4]}\end{array}$ & $20 / F$ & OS & $\begin{array}{l}\text { Inferonasal epibulbar nodule }(5 \times 5 \mathrm{~mm}) \text {, } \\
\text { panuveitis, subretinal exudate }\end{array}$ & Pelvic mass & $\begin{array}{l}\text { Excision + Oral \& topical } \\
\text { steroid }\end{array}$ & Yes \\
\hline $\begin{array}{l}\text { Shah, } 2012 \\
{[12]}\end{array}$ & $36 / F$ & OS & $\begin{array}{l}\text { Superior epibulbar nodule }(12 \times 20 \mathrm{~mm}) \text {, } \\
\text { trace anterior uveitis }\end{array}$ & Nil & $\begin{array}{l}\text { Excision + Oral \& topical } \\
\text { steroid + oral cyclosporine }\end{array}$ & Yes \\
\hline \multirow[t]{3}{*}{$\begin{array}{l}\text { Choi, } 2018 \\
{[2]}\end{array}$} & $35 / \mathrm{M}$ & OU & $\begin{array}{l}\text { Epibulbar masses, retinal detachment, } \\
\text { and choroidal effusions }\end{array}$ & $\begin{array}{l}\text { Sinus, trachea, renal, } \\
\text { subcutaneous skin lesions }\end{array}$ & $\begin{array}{l}\text { Cladribine, steroids, } \\
\text { mycophenolate mofetil, } \\
\text { rituximab, vemurafenib }\end{array}$ & Yes \\
\hline & $54 / F$ & $\mathrm{OU}$ & Epibulbar masses & $\begin{array}{l}\text { Colon lesions, peritoneum, soft } \\
\text { tissue of chest wall }\end{array}$ & Excision & Unknown \\
\hline & $41 / F$ & $\mathrm{OU}$ & Epibulbar masses & $\begin{array}{l}\text { Lung, aortic lymph nodes, } \\
\text { pleura, skeletal (rib) }\end{array}$ & Steroid & Unknown \\
\hline $\begin{array}{l}\text { Lee, } 2018 \\
\text { (Present } \\
\text { case) }\end{array}$ & $36 / M$ & OS & $\begin{array}{l}\text { Antecedent uveitis and anterior nodular } \\
\text { scleritis, inferotemporal epibulbar mass }\end{array}$ & $\begin{array}{l}\text { Facial skin nodule, multiple } \\
\text { papulonodules on bilateral } \\
\text { cheek, ear and scalp }\end{array}$ & $\begin{array}{l}\text { Excision + Oral \& topical } \\
\text { steroid, methotrexate }\end{array}$ & No \\
\hline
\end{tabular}

Abbreviation: $F$ female, $M$ male, $O D$ right eye, $O S$ left eye, $O U$ both eyes

highlighting the importance of the administration of systemic therapy.

Cutaneous Rosai-Dorfman disease can be successfully treated with oral dapsone according to the study by Chan $\mathrm{CC}$ et al [18]. Chan demonstrates that numerous neutrophils and histiocytes with a positive myeloperoxidase staining are detected in specimens obtained from patients with cutaneous Rosai-Dorfman disease. As in our present case, multiple neutrophils and histiocytes were found in the pathology of the skin biopsy. Because dapsone exerts anti-inflammatory effects through inhibition of myeloperoxidase, which is present in the azurophilic granules of neutrophils, as well as in the lysosomes of monocytes, tissueresident macrophages and histiocytes, it is one of the effective treatment options for cutaneous Rosai-Dorfman disease.

Immunosuppressive therapy could possibly worsen the Demodex infestations. An in vivo study reveals that Demodex mites rapidly colonize genetically modified mice (BALB/c-
IL13/IL4) with an impaired Th2 response [19]. Thus, if the immunosuppressive therapy causes a shift from a Th2 to a Th1/Th17 immune response, it is possible the number of Demodex mites will increase. In a study describing dupilumab therapy as the culprit of rosacea, the author speculated that inhibition of the Th2 pathway by dupilumab may actually induce an overgrowth of Demodex mites and may play a role in the pathogenesis of rosacea [20].

In conclusion, we believe that scleritis and anterior uveitis should be considered as presenting signs of RDD. This subtype of extranodal RDD is characterized by a poor response to corticosteroid therapy, the formation of an epibulbar mass months later, and the absence of cervical lymphadenopathy. Because of its complexity, a multidisciplinary team is necessary for optimal patient care, and a surgical excision combined with a maintenance regimen of systemic therapy is feasible to control the disease without recurrence. 


\section{Abbreviations}

MTX: methotrexate; RDD: Rosai-Dorfman disease

\section{Acknowledgements}

Not applicable.

\section{Authors' contributions}

YKL, SCC, CNL, and JHH were responsible for substantial contributions to the conception or design of the work, and the acquisition of the data. YKL, SCC, $\mathrm{CNL}$, and $\mathrm{JHH}$ were responsible for the interpretation of results. YKL and JHH participated in the design and were major contributors in writing the manuscript. YKL, SCC, CNL, and JHH were responsible for final approval of the version to be published. All authors reviewed and approved the final manuscript.

\section{Funding}

This study was supported by a grant from National Cheng Kung University Hospital, Tainan, Taiwan (NCKUH-10802016 to J.H.H.)

\section{Availability of data and materials}

All data generated or analyzed during this study are included in this published article.

\section{Ethics approval and consent to participate}

The need for approval was waived due to de identification.

\section{Consent for publication}

Written informed consent for publication of his clinical details and clinical images was obtained from the patient.

\section{Competing interests}

The authors declare that they have no competing interests.

\section{Author details}

'Department of Ophthalmology, National Cheng Kung University Hospital, College of Medicine, National Cheng Kung University, Tainan, Taiwan. ${ }^{2}$ Department of Dermatology, National Cheng Kung University Hospital, College of Medicine, National Cheng Kung University, Tainan, Taiwan. ${ }^{3}$ Institute of Clinical Medicine, College of Medicine, National Cheng Kung University, Tainan, Taiwan.

Received: 2 February 2019 Accepted: 5 July 2019

Published online: 10 July 2019

\section{References}

1. Abla O, Jacobsen E, Picarsic J, Krenova Z, Jaffe R, Emile JF, Durham BH, Braier J, Charlotte F, Donadieu J, et al. Consensus recommendations for the diagnosis and clinical management of Rosai-Dorfman-Destombes disease. Blood. 2018;131(26):2877-90.

2. Choi MB, Salomao DR, Smith WM, Pulido JS, Garrity JA. Ophthalmic findings of Rosai-Dorfman disease. Am J Ophthalmol. 2018;188:164-72.

3. de Oliveira RC, Rigueiro M, Vieira AC, de Freitas D, Sato E. Rosai-Dorfman disease manifesting as an epibulbar ocular tumour. Clin Exp Ophthalmol. 2011;39(2):175-7.

4. Payne JF, Srivastava SK, Wells JR, Grossniklaus HE. Rosai-Dorfman disease simulating nodular scleritis and panuveitis. Arch Ophthalmol. 2011;129(4):518-20.

5. Foucar E, Rosai J, Dorfman RF. The ophthalmologic manifestations of sinus histiocytosis with massive lymphadenopathy. Am J Ophthalmol. 1979;87(3):354-67.

6. Zimmerman LE, Hidayat AA, Grantham RL, Chavis RM, Stopak SS, Dreizen NG, O'Neill JF. Atypical cases of sinus histiocytosis (Rosai-Dorfman disease) with ophthalmological manifestations. Trans Am Ophthalmol Soc. 1988:86:113-35.

7. Tan HY, Kao LY. Rosai-Dorfman disease manifesting as relapsing uveitis and subconjunctival masses. Chang Gung Med J. 2002;25(9):621-5.

8. Albini TA, Evans M, See R, Rao NA, Marback E, de Souza MM. Rosai-Dorfman disease: isolated epibulbar masses in two adult patients. Br J Ophthalmol. 2005:89(2):241-3.

9. Sarwal R, Tu E, Mendelblatt FI, Sugar J, Gross SA, Pulido JS, Edward DP Atypical ocular presentations of Rosai-Dorfman disease. Ocul Immuno Inflamm. 2008;16(1):9-15.
10. Fernandes BF, Brazuna A, Moura LR, Ayres B, Nakamura P, Al-Kandari AA Burnier MN Jr. Extranodal Rosai-Dorfman disease presenting as an epibulbar tumor. Cornea. 2008;27(3):378-81.

11. Maheshwari R, Shekde S. Extranodal Rosai-Dorfman disease presenting as an isolated epibulbar mass. Indian J Ophthalmol. 2008;56(6):502-4.

12. Shah A, Bielory L, Mirani N, Tu Y, Chu DS. Epibulbar rosai-dorfman disease: novel manifestation and treatment. Arch Ophthalmol. 2012;130(9):1218-20.

13. Fang S, Chen A-J. Facial cutaneous Rosai-Dorfman disease: a case report and literature review. Experimental and therapeutic medicine. 2015:9(4):1389-92.

14. Brenn T, Calonje E, Granter SR, Leonard N, Grayson W, Fletcher CD, McKee $\mathrm{PH}$. Cutaneous rosai-dorfman disease is a distinct clinical entity. Am J Dermatopathol. 2002;24(5):385-91.

15. Lacey N, Russell-Hallinan A, Zouboulis CC, Powell FC. Demodex mites modulate sebocyte immune reaction: possible role in the pathogenesis of rosacea. Br J Dermatol. 2018;179(2):420-30.

16. Konca C, Ozkurt ZN, Deger M, Aki Z, Yagci M. Extranodal multifocal RosaiDorfman disease: response to 2-chlorodeoxyadenosine treatment. Int J Hematol. 2009;89(1):58-62

17. Visser K, Katchamart W, Loza E, Martinez-Lopez JA, Salliot C, Trudeau J, Bombardier C, Carmona L, van der Heijde D, Bijlsma JW, et al. Multinational evidence-based recommendations for the use of methotrexate in rheumatic disorders with a focus on rheumatoid arthritis: integrating systematic literature research and expert opinion of a broad international panel of rheumatologists in the 3E initiative. Ann Rheum Dis. 2009;68(7):1086-93.

18. Chan CC, Chu CY. Dapsone as a potential treatment for cutaneous Rosai-Dorfman disease with neutrophilic predominance. Arch Dermatol. 2006;142(4):428-30.

19. Smith PC, Zeiss CJ, Beck AP, Scholz JA. Demodex musculi infestation in genetically Immunomodulated mice. Comp Med. 2016;66(4):278-85.

20. Heibel HD, Hendricks AJ, Foshee JP, Shi VY. Rosacea associated with Dupilumab therapy. J Dermatolog Treat. 2019:9:1-12.

\section{Publisher's Note}

Springer Nature remains neutral with regard to jurisdictional claims in published maps and institutional affiliations.

Ready to submit your research? Choose BMC and benefit from:

- fast, convenient online submission

- thorough peer review by experienced researchers in your field

- rapid publication on acceptance

- support for research data, including large and complex data types

- gold Open Access which fosters wider collaboration and increased citations

- maximum visibility for your research: over $100 \mathrm{M}$ website views per year

At BMC, research is always in progress.

Learn more biomedcentral.com/submissions 